\title{
Coactivation of Prefrontal Cortex and Inferior Parietal Cortex in Working Memory Tasks Revealed by 2DG Functional Mapping in the Rhesus Monkey
}

\author{
Harriet R. Friedman and Patricia S. Goldman-Rakic \\ Section of Neurobiology, Yale University School of Medicine, New Haven, Connecticut 06510
}

Functional studies of the dorsolateral prefrontal cortex and the inferior parietal lobe of the rhesus monkey have implicated the former in spatial mnemonic function and the latter in visuospatial processing. We used the ${ }^{14} \mathrm{C}$-2-deoxyglucose (2DG) method to assess the contribution of these cortical regions to the cognitive performance of monkeys on working memory tasks. In these experiments, one group of monkeys (WORK) was trained to perform tasks (delayed spatial alternation, spatial delayed response, or delayed object alternation) that specifically engaged working memory processing. Local cerebral glucose utilization (LCGU) rates in the WORK group was compared with LCGU rates for a second group of monkeys (CONT) tested on one of two tasks (visual pattern discrimination or sensory-motor) that relied upon associative memory.

The results showed that in comparison to the CONT group, working memory performance significantly enhanced LCGU by $19 \%$ in the principal sulcus region of prefrontal cortex and by $11-20 \%$ in regions of the inferior parietal cortex corresponding to areas $7 \mathrm{~A}, 7 \mathrm{~B}, 7 \mathrm{IP}$, and $7 \mathrm{M}$. By contrast, LCGU in the auditory cortex was similar for both groups. In all areas examined, metabolic activation peaked in lower layer III where the majority of associational and callosal neurons lie. Correlation analyses of LCGU and behavioral task parameters indicated that LCGU in the parietal subdivisions was significantly related either to the accuracy of performance or to the number of trials completed on the 2DG test. In contrast, LCGU in the principal sulcus was positively correlated with task difficulty. These findings suggest that the enhancement of LCGU in the principal sulcus was primarily influenced by the mnemonic components of the tasks whereas LCGU in the inferior parietal cortex was influenced by their sensory-motor demands.

These are the first results showing concurrent metabolic activation of the prefrontal and parletal cortex in monkeys performing working memory tasks and they support the suggestion that these cortical regions represent two important

\footnotetext{
Received June 11, 1993; revised Oct. 11, 1993; accepted Oct. 26, 1993.

This work was supported in part by U.S. Public Health Service Award R37MH38546 and by ONR Award N00014-91-J-1251. We thank JoAnn Coburn and Mariamma Pappy for their expert technical assistance, Jamie Mazer for computer programming and his assistance in data collection, and Gary Leydon for computer programming.

Correspondence should be addressed to Harriet R. Friedman, Ph.D., Section of Neurobiology, C303, Yale University School of Medicine, 333 Cedar Street, New Haven, CT 06510.

Copyright (C) 1994 Society for Neuroscience $0270-6474 / 94 / 142775-14 \$ 05.00 / 0$
}

nodes in a neural network mediating spatial working memory in the monkey (Goldman-Rakic, 1988). Further, the present report reinforces the power of the 2DG method for functional mapping as these areal and laminar results could not be readily appreciated at this resolution in any other methodological context.

IKey words: principal sulcus, inferior parietal cortex, 2-deoxyglucose, working memory, spatial memory, metabolic activityl

Since the studies of Jacobsen (1936), dorsolateral prefrontal cortex has been associated with the capacity to perform delayedresponse tasks in the nonhuman primate. Subsequent experiments in the monkey have served to refine the explicit nature of the impairment following prefrontal cortex damage while also delimiting the extent of the cortical area involved in delayedresponse performance to the region of the principal sulcus. The impairment of monkeys with dorsolateral lesions on the two classic tests of prefrontal cortex function, the spatial delayed response task and the spatial delayed alternation task (Goldman and Rosvold, 1970; Goldman et al., 1971), has been specifically related to working memory processing in the spatial domain (Goldman-Rakic, 1987). These tasks require a flexible shortterm storage mechanism whereby relevant information can be maintained on line and replaced or updated on a trial-by-trial basis as the demands of the task stipulate.

Several lines of anatomical and electrophysiological evidence have long indicated that the principal sulcus and the association cortex of the inferior parietal lobule have intersecting functional domains. Anatomical connections between the prefrontal and inferior parietal association cortices are particularly dense (e.g., Mesulum et al., 1977; Pandya and Seltzer, 1982; Petrides and Pandya, 1984; Cavada and Goldman-Rakic, 1989) and these two regions have common cortical and subcortical target regions (Selemon and Goldman-Rakic, 1988). Studies of monkeys sustaining inferior parietal cortex damage emphasize the importance of this cortex for visuospatial processing (e.g., Pohl, 1973; Ungerleider and Brody, 1977; Petrides and Iversen, 1978) and visuospatial processing represents a functional nexus between the principal sulcus and inferior parietal cortex (e.g., GoldmanRakic, 1988; Quintana and Fuster, 1993). Indeed, on the cellular level, electrophysiological studies show remarkable similarities in the responses of neurons in the two regions while monkeys are performing visuospatial perceptual and visuospatial memory tasks involving oculomotor (Gnadt and Anderson, 1988; Funahashi et al., 1989, 1990; Goldman-Rakic et al., 1993) or manual responses (Quintana et al., 1988; Koch and Fuster, 1989). 
In the present study, we further investigated the functional interdependence of the dorsolateral prefrontal and inferior parietal cortices for performance on working memory tasks in the rhesus monkey using the 2-deoxyglucose (2DG) method (Sokoloff et al., 1977). Metabolic activity was measured in the posterior half of the principal sulcus region of the dorsolateral prefrontal cortex and in four architectonic subdivisions of the inferior parietal cortex corresponding to 7IP, 7A, 7B, and 7M (see Cavada and Goldman-Rakic, 1989). Local cerebral glucose utilization (LCGU) rates in these cortices for monkeys performing working memory tasks were compared with LCGU rates in the same brain regions of monkeys performing control tasks that specifically did not engage working memory.

In a previous report, LCGU rates were shown to be enhanced by working memory processing in the hippocampus and dentate gyrus (Friedman and Goldman-Rakic, 1988) and in the anterior and dorsomedial thalamic recipient regions of dorsolateral prefrontal cortex projections (Friedman et al., 1990b). As argued above, the preeminent involvement of dorsolateral prefrontal cortex in delayed response-type tasks leads to the expectation that the principal sulcus will be selectively activated during performance of working memory tasks as compared to associative memory tasks. Likewise, although the inferior parietal cortex has not been specifically implicated in working memory performance previously, its anatomical interconnections and functional involvement in visuospatial processing lead us to predict that it will be similarly activated in working memory task performance in the monkey because it is an essential node in a spatial cognition network (e.g., Mountcastle et al., 1975; Selemon and Goldman-Rakic, 1988).

A portion of these results has been reported previously in abbreviated form (Friedman et al., 1991).

\section{Materials and Methods}

\section{Subjects}

Fifteen individually housed male rhesus monkeys (Macaca mulatta, $2.0-6.0 \mathrm{~kg}$ ) were trained to perform either a working memory or a control task. Monkeys were fed a diet of monkey chow and fruit that was adjusted to stabilize performance; water was always available. Throughout the experiment, body weight was maintained at $90 \%$ or better.

\section{Apparatus and test procedures}

Monkeys were seated in a primate chair and tested in a modified Wisconsin General Testing Apparatus (WGTA) inside a darkened, soundshielded room. The WGTA contained a wooden test tray $(22 \mathrm{~cm} \times 50$ $\mathrm{cm}$ ) with two recessed wells for rewards (raisins, peanuts, and other bite-sized treats). An opaque screen was lowered to prevent access to the test tray during scheduled temporal delays and intertrial intervals. A white noise generator supplied a constant level $(90 \mathrm{~dB})$ of background noise during testing sessions.

The training regimen for the specific tasks used has been described prcviously (Pribram and Mishkin, 1956; Goldman, 1971; Mishkin and Manning, 1978; Friedman and Goldman-Rakic, 1988) and is only briefly reviewed here. All monkeys were chair trained, habituated to the WGTA, and taught to displace cardboard plaques $(8 \mathrm{~cm} \times 8 \mathrm{~cm})$ or objects (a blue wooden box, $6.5 \mathrm{~cm}$ square $\times 3 \mathrm{~cm}$ high, and a green cylinder, $6.5 \mathrm{~cm}$ diameter $\times 8 \mathrm{~cm}$ high) to obtain a food reward from the recessed food well in the test tray. The specific training procedures used were tailored to each monkey to facilitate learning. Monkeys were initially trained on their task using short delay or intertrial intervals (1$2 \mathrm{sec}$ ) and short session lengths (approximately $20 \mathrm{~min}$ ). Once a monkey demonstrated proficiency on its task, the intertrial interval or delay, the number of trials per session, and the duration of test sessions were gradually increasing until the monkey performed its assigned task accurately and steadily at the desired delay/intertrial interval through a 45-50 min test period as required for the $2 \mathrm{DG}$ protocol.

Nine monkeys were trained on one of three tasks that specifically engaged working memory: spatial delayed response (DR), spatial delayed alternation (DA), and delayed object alternation (DOA). These tasks differ in their explicit task demands, for example, the occasion of a cue period and whether the response is to be made to an object or directed at a particular spatial location. However, the three tasks similarly represent sequential trial-by-trial tests in which performance on any current trial must be guided by the memory of stimulus events occurring in the just-preceding trial. Importantly, there is no constant stimulus-response association that may be relied upon instead. Two of these working memory tasks, DR and DA, had explicit spatial contingencies. For the DR task, one food well [right or left, as given by a Gellerman series (1933)] was baited in full view of the monkey (cue phase); both wells were covered with identical plaques and then the opaque screen was lowered. Monkeys $(N=2)$ were required to displace the correct plaque to obtain the reward when the screen was raised after a $12 \mathrm{sec}$ delay period. In the DA task, one well was baited and both were covered by identical plaques out of the view of the monkey. These monkeys were required to remember over the intertrial interval the position of the bait on the previous trial and to select the alternate well on succeeding trials. Two intertrial intervals were used: $12 \sec (N=2)$ and $30 \sec (N=2)$.

In the third working memory paradigm, DOA, monkeys $(N=3)$ were trained to obtain the reward on the basis of features of objects rather than spatial location. In this task, one of two distinct objects covered the baited well on alternate trials. Monkeys were required to remember over a $12 \mathrm{sec}$ intertrial interval which object had covered the baited well on the previous trial, and to select the alternate object on successive trials. Spatial position was irrelevant because the position of the baited object varied from trial to trial as given by a Gellerman series (1933). The objects were a blue wooden cube and a green plastic cylinder. Monkeys learned this task in stages (e.g., Mishkin and Manning, 1978): they were first trained to perform an object discrimination reversal task, and gradually this task was transformed into object alternation by decreasing the number of trials before reversal.

The data for monkeys tested on the working memory paradigms (the WORK group) were compared with the results for six monkeys tested on one of two control paradigms (the CONT group). These control tasks did not specifically engage working memory but instead relied on association memory because monkeys learned a fixed association between a particular stimulus and a particular response. For the visual pattern discrimination task (VD), monkcys $(N=4)$ wcrc trained to associate one of two visual stimuli with the baited well. These stimuli were: a plaque showing a white plus-sign on a black background, and a plaque showing a white square on a black background. The plaque showing the plus sign always covered the baited well. The spatial position of these stimuli on the test tray was varied using a Gellerman (1933) series; however, spatial location was irrelevant for the solution of the task. A $10 \mathrm{sec}$ delay separated all trials. The remaining monkeys in the CONT group $(N=2)$ were tested on a sensory-motor control paradigm (SMC) in which one or both wells were baited and covered with plaques on each trial, and the monkey was always permitted to retrieve the bait. Although there was no explicit memory requirement in this task because the reward was provided on each trial, all of its other sensory and motor components were similar to the other tasks, even to the extent that the opaque screen was lowered betwecn trials for a $12 \mathrm{scc}$ intertrial interval.

\section{$2 D G$ procedures}

The quantitative 2DG method described by Sokoloff et al. (1977) was followed. All monkeys received arterial and venous catheters that were inserted into the femoral vessels while monkeys were anesthetized with a mixture of nitrous oxide and halothane gas in conjunction with local anesthetics. Six monkeys were given ketamine $(5 \mathrm{mg} / \mathrm{kg})$ in addition to the gas anesthesia and the catheters were inserted in an aseptic procedure $24 \mathrm{hr}$ prior to the $2 \mathrm{DG}$ experiment. The remaining monkeys received catheters several hours prior to the 2DG experiment and sat in the primate chair for at least $2 \mathrm{hr}$ afterward to recover from the anesthesia.

\section{Experimental session}

About 3-5 min into the test session, the ${ }^{14} \mathrm{C}-2 \mathrm{DG}(100 \mu \mathrm{Ci} / \mathrm{kg}$ in $1 \mu \mathrm{Ci} /$ $10 \mu \mathrm{l}$ sterile saline, $50-60 \mathrm{mCi} / \mathrm{mm}$; American Radiolabelled Chemicals) was intravenously injected followed by a saline flush. Arterial blood samples were taken at timed intervals over the next $45 \mathrm{~min}$. At the end of the 45 min testing interval, the monkey was killed with an overdosc of sodium pentobarbital. In four cases, the brain was rapidly removed, 
sectioned into blocks, and frozen by immersion in isopentane $\left(-40^{\circ} \mathrm{C}\right)$. All other monkeys were first perfused intracardially with $3.3 \%$ paraformaldehyde because this consistently improved the quality of the tissue.

\section{Tissue processing}

Brain tissue was stored at $-70^{\circ} \mathrm{C}$ until sectioned at $20 \mu \mathrm{m}$ on a Bright (Hacker Instruments, Huntingdon, England) cryostat at $-22^{\circ} \mathrm{C}$. Four conseculive sections were saved at $400 \mu \mathrm{m}$; three of these (triplets) were collected on cold coverslips, rapidly dried on a hot plate, taped to cardboard, and exposed to x-ray film (SB5, Kodak) for 8-10 d together with a set of plastic ${ }^{14} \mathrm{C}$ standards $(0-1.08 \mathrm{Ci} / \mathrm{gm}$; Amersham). Films were processed using GBX (Kodak) developer and fixative. The fourth section was saved on a slide, dried on the hot plate, and stained with cresyl violet.

\section{Blood glucose and ${ }^{14} \mathrm{C}$ levels}

Arterial blood samples were centrifuged and $20 \mu \mathrm{l}$ plasma samples were analyzed for glucose concentration (Beckman Glucose Analyzer 2) and for ${ }^{14} \mathrm{C}$ concentration (Beckman scintillation counter) immediately after the experiment. Integrated arterial plasma specific activities derived from the blood concentration curves were used to convert tissue ${ }^{14} \mathrm{C}$ concentrations to local cerebral glucose utilization (LCGU) values (Kennedy et al., 1978).

\section{Analysis of autoradiographs}

Autoradiographs of brain sections, together with each film's set of ${ }^{14} \mathrm{C}$ standards, were digitized using a computerized video-image processing system (e.g., Friedman and Goldman-Rakic, 1988). The computer used these standards to quantify radioactivity in each brain image by translating pixel-gray values to ${ }^{14} \mathrm{C}$ radioactivity levels; these levels were converted to LCGU rates using the integrated plasma specific activities obtained for each monkey.

\section{Brain regions sampled for $L C G U$}

Principal sulcus. LCGU was measured bilaterally through the posterior $8-10 \mathrm{~mm}$ of the principal sulcus of the prefrontal cortex. This region represents nearly the entire posterior half of the principal sulcus and usually was represented in 18-20 autoradiograph triplets per monkey. Because of tissue artifacts, only 14 triplets could be examined for one monkey of the WORK group. To obtain LCGU rates for the principal sulcus, a series of distinct computer-generated box outlines was arranged across each bank in digitized autoradiographs (visualized on a video monitor) using a manual cursor and a bit pad. The region highlighted in Figure 1 (top) depicts the area encompassed by a typical box array (see also Fig. 2). The height of these boxes was set to include cortical layers II-V and individual boxes were uniquely associated with particular portions of the principal sulcus, for example, box l-ventrolateral rim (see Fig. 2). This arrangement was kept relatively constant so that the region of the principal sulcus outlined for measurement was consistent across all monkeys. The use of this box array procedure was dictated partly by the available software and partly by its flexibility because it allowed us to measure LCGU in the principal sulcus overall and, by regrouping individual boxes, to measure LCGU in subregions of the principal sulcus corresponding to the topography of prefrontalparietal projections (see below).

Once a box array was configured, the computer automatically generated LCGU rates for the separate areas outlined by each box. These data were either stored on line and then electronically transferred to a database or manually transcribed to the database from computer printouts. Figure 2 shows the methods used to derive LCGU rates for a cortical region of interest from the box arrays. As depicted in the cartoon, each autoradiograph in a triplet yielded an array of data boxes (e.g., boxes 1-10, 1'-10', 1', 10" in Fig. 2). First, the median LCGU rate for corresponding boxes within a triplet was determined [e.g., median $\left(1,1^{\prime}, 1^{\prime \prime}\right)$, median $\left(10,10^{\prime}, 10^{\prime \prime}\right)$ in Fig. 2]. Second, these medians were arithmetically averaged to yield the LCGU rate for the entire principal sulcus at that particular $400 \mu \mathrm{m}$ interval. Finally, the median of all LCGU means across the entire anterior-posterior extent of the measurement region was determined to obtain the LCGU rate for the principal sulcus of each monkey and these data were used for further statistical analysis.
To obtain LCGU rates for subregions of the principal sulcus representing selective areas targeted by parietal projections, the individual components of the box array were regrouped to best approximate the topography reported by Cavada and Goldman-Rakic (1989, their Fig. 15). Thus, selected boxes within a triplet were grouped to compose these subareas and their medians were averaged to yield the LCGU rate for each subarea at each $400 \mu \mathrm{m}$ interval. All other procedures werc identical to those described.

Parietal cortex. LCGU was measured bilaterally in four cytoarchitectonic subdivisions of the posterior parietal cortex: areas $7 \mathrm{~B}$ and $7 \mathrm{~A}$ on the surface of the parietal gyrus; area $7 \mathrm{M}$, located medially; and area 7IP, comprising the inferior bank of the intraparietal sulcus (Fig. 1). As described by Cavada and Goldman-Rakic (1989), this parcellation of the posterior parietal cortex is both historically and cytoarchitectonically consistent with previous studies (e.g., von Bonin and Bailey, 1947; Pandya and Seltzer, 1982). For 7IP, the anterior-posterior extent of the measurement region averaged $12 \mathrm{~mm}$ (30 autoradiograph triplets), commencing anteriorly, at the level of the central sulcus, and continuing through the most posterior aspect of the lateral sulcus. Measurements of areas $7 \mathrm{~A}$ and $7 \mathrm{~B}$ of the inferior parietal gyrus were taken through the same cortical territory. For examination of LCGU rates in $7 \mathrm{M}$, mcasurements were largely confined to the anterior $4 \mathrm{~mm}$ of this medial cortex as the sulcal landmarks at this level rendered the territory of $7 \mathrm{M}$ least ambiguous. The inferior parietal lobule could not be analyzed in one monkey (CONT group) due to uniformly poor tissue quality in this brain block.

As described for the principal sulcus, separate box arrays were constructed to outline the parietal regions of interest with box height set to include cortical layers II-V. The procedures used to obtain LCGU rates for these parietal subdivisions were identical to those described above. Because the exact boundaries of 7B and 7A were difficult to ascertain for each monkey without greatly truncating the boundaries of these regions, we did not separately analyze the data for $7 \mathrm{~B}$ and $7 \mathrm{~A}$. Instead, the entire anterior-posterior expanse of $7 \mathrm{~B}$ through $7 \mathrm{~A}$ was considered as a unit, 7A and 7B; thus, the LCGU data are given for the gyrus as a whole.

Auditory cortex. The cortical auditory area of the Sylvian fissure was measured as an additional region of interest. LCGU in auditory cortex was not expected to be sensitive to the mnemonic demands of the different behavioral tasks and it was always contained within the series of autoradiographs digitized for the parietal cortex. Autoradiographs spanning the central $3.0 \mathrm{~mm}$ (anterior-posterior) of auditory cortex (corresponding to Kam and Kalt of Pandya and Sanides, 1973) were included in this analysis (Fig. 1). In this region also, box arrays were constructed to include the middle cortical layers (II-V). The auditory cortex for one monkey could not be measured because of poor tissue quality (the same monkey as was eliminated from the parietal measurements, see above).

\section{Laminar analysis}

For each region of interest, the laminar pattern of 2DG uptake was examined by comparing a subset of autoradiographs with adjacent brain sections that had been saved on slides and stained with cresyl violet (CV sections). These autoradiographs and the adjacent $\mathrm{CV}$ sections were digitized at the same (high) magnification, aligned using manual and computational methods, and stored. Printed images of CV sections and adjacent autoradiographs were obtained using a thermal printer (Tektronix 4693DX). Laminae designations made on the printed CV images were confirmed by microscopic examination of the CV sections; these were then transcribed onto the printed autoradiograph images to identify the pattern of 2DG uptake. This information was used to "landmark" layers I, IV, and VI on the digitized autoradiographs. To obtain a quantitative depiction of LCGU across these layers, points (splines) were placed in a vertical column to demarcate cortical depth (laminae) on stored digitized autoradiograph images using a manual cursor and bitpad (e.g., Friedman et al., 1990a). The width of these "columns" was standardized at $1 \mathrm{~mm}$. A computer algorithm automatically computed the average ${ }^{14} \mathrm{C}$ radioactivity values across the cortical width for each pixel of its depth using the ${ }^{14} \mathrm{C}$ standards of each image. The $\mathrm{x}$-y coordinates of the column, radioactivity values, as well as landmark symbols designating particular layers were stored and electronically transferred to a database wherein the radioactivity values were translated to LCGU rates using the integrated plasma specific activities obtained for each monkey. These rates were linearly plotted as a function of cortical depth with the laminar landmarks indicated using commercial software. 


\section{Prefrontal Cortex}

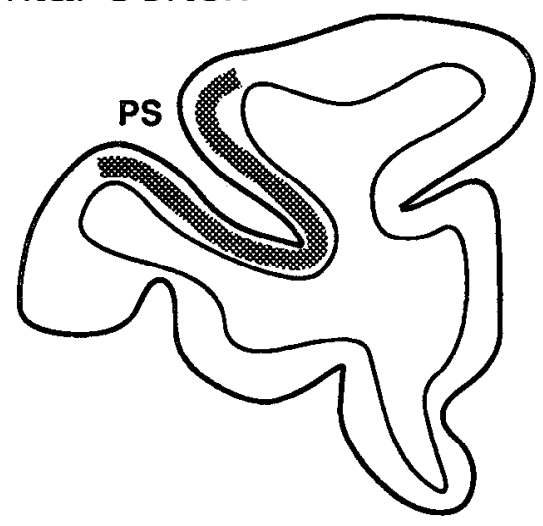

\section{Inferior Parietal Cortex}

Figure 1. Cortical outlines of representative coronal brain sections from three anterior-posterior levels showing the prefrontal, parietal, and auditory cortical regions from which glucose utilization measurements were taken. The shaded contours in each outline show the area encompassed by the measurement box arrays for the principal sulcus $(P S ; t o p)$, the anterior inferior parietal area (subarea $7 B$ and a portion of subarea $7 I P$ ) and the auditory cortex ( $m i d$ $d l e$, and the more posterior inferior parietal area (subareas $7 A, 7 M$, and a portion of subarea $7 I P$; bottom). LS, lateral sulcus.

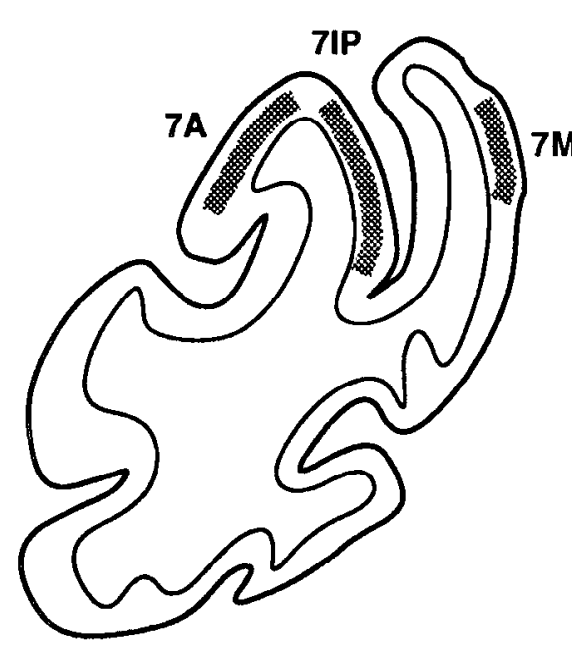

\section{Statistical analysis}

To determine whether LCGU in the principal sulcus, inferior parietal cortex, and auditory cortex was influenced differently by behavioral performance on tasks that specifically engage working memory, the LCGU data for the WORK group were compared to the LCGU data of the CONT group for each cortical area by analysis of covariance (Winer, 1971). The covariance model was used principally to control for individual differences in overall brain metabolism (Friedman and Goldman-Rakic, 1988; Friedman et al., 1990). This analysis was implemented using a computer-based statistical package (SYSTAT, Inc., Sherman, IL). The covariate used was the LCGU of the medial geniculate body because this thalamic auditory nucleus was not likely to be differentially influenced by the separate tasks as the same white masking noise was present during all experiments. Indeed, the average LCGU (in $\mu \mathrm{mol} / 100 \mathrm{gm} / \mathrm{min}$ ) for the medial geniculate was similar for both groups, being 76.21 for the nine monkeys of the WORK group and 73.96 for the six monkeys of the CONT group; this group difference was not significant by an analysis of variance $[F(1,13)=0.12$, NS $]$. To retain the consistency of the covariance model across other planned comparisons, such as for within-group Pearson Product Moment correlations between particular task parameters and LCGU, the ratio of an individual monkey's cortical LCGU to its medial geniculate LCGU was used.

\section{Results}

On the 2DG test date, the performance score of individual monkeys ranged from $73 \%$ to $100 \%$ correct, the WORK group mean score was $86 \%$ correct, and the CONT group mean score was $98 \%$ correct (Table 1; scores for the CONT group include only monkeys tested on the VD task). Grouped by individual tasks, mean performance scores were $80 \%$ correct or better. Interestingly, the rank order of these means for the WORK tasks parallels a rating of their relative difficulty as based on the number of training sessions needed for monkeys to achieve criterion performance on elementary versions (short delay intervals) of each task (Friedman and Goldman-Rakic, 1988). By this ranking, the DOA task was the most difficult: training required more sessions on average than all other tasks, and the mean performance score for the monkeys performing this task was lower relative to the other tasks (the pitfalls of training monkeys to perform this task were described by Mishkin and Manning, 1978). Second to the DOA task, monkeys had the most difficulty learning the DA task. Indeed, the two monkeys that did not perform with at least $80 \%$ accuracy on the $2 \mathrm{DG}$ session were tested on the DOA and DA ( $30 \mathrm{sec}$ delay) tasks (Table 1). The DR task was the least difficult among the WORK tasks and actually required fewer sessions on average to acquire than the VD task (Table 1). The SMC task, having no mnemonic requirement, was the least difficult task for monkeys to acquire. The number of trials completed by each monkey during the 2DG session depended upon the delay or intertrial interval used (Table 1). In the tasks using a 10 or $12 \mathrm{sec}$ delay/intertrial interval, therefore excluding the DA task using a 30 sec delay, the average number of trials completed for the WORK group (142 trials) was approximately the same as for the CONT group (145 trials). The two monkeys performing the DA task with 30 $\mathrm{sec}$ intertrial intervals completed roughly half this number of 


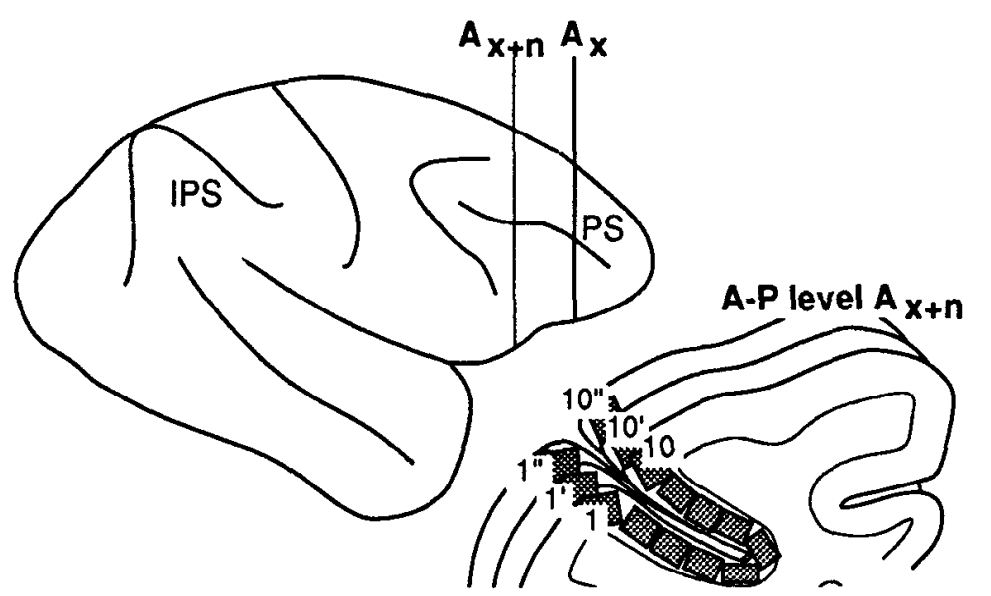

$\operatorname{LCGU~A}_{\mathbf{x}+\mathbf{n}}=$ Average $\left[\left(\right.\right.$ Median $\left(1,1^{\prime}, 1^{\prime \prime}\right)$, , , Median $\left.\left(10,10^{\prime}, 10^{\prime \prime}\right)\right]$

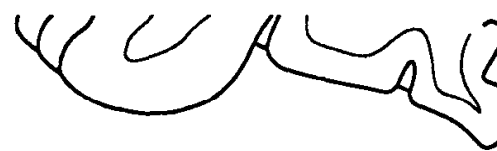

A-P level A
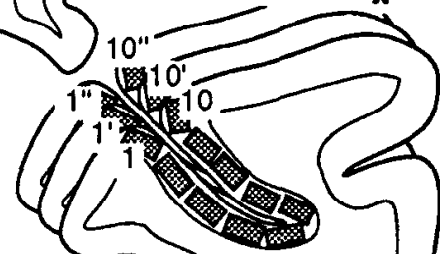

LCGU A $\mathbf{X}=$ Average $\left[\left(\right.\right.$ Median $\left(1,1^{\prime}, 1^{\prime \prime}\right), \ldots$, Median $\left.\left(10,10^{\prime}, 10^{\prime \prime}\right)\right]$

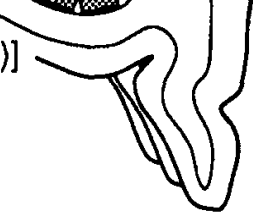

Principal Sulcus LCGU $=$ Median $(,$, Average A $\mathbf{x},,$, Average A $\mathbf{x}+\mathbf{n},,$, )
Figure 2. The box array method for determining LCGU rates across the anterior-posterior extent of a cortical region of interest. The lateral view of the brain (top) shows two anterior-posterior $(A-P)$ levels representing the coronal brain sections drawn below. At each A-P level, three adjacent autoradiographs are analyzed. Here, an analogous array of boxes is placed along the principal sulcus $(P S)$ of cach autoradiograph component of a triplet (1-10, $1^{\prime}-$ $\left.10^{\prime}, 1^{\prime \prime}-10^{\prime \prime}\right)$. Medians of corresponding boxes $\left[\left(1,1^{\prime}, 1^{\prime \prime}\right),,\left(10,10^{\prime}, 10^{\prime \prime}\right)\right]$ are computed and these medians are averaged to yield LCGU for the principal sulcus at individual A-P levels. The median of these averages, across the A-P extent of the measurement region, represents the LCGU of the principal sulcus for individual monkeys. IPS, intraparietal sulcus. trials (mean $=75$ ). These performance variables: trials completed, performance scores, and task difficulty, are further examined below in conjunction with the LCGU data.

A final salient point about the behavioral training concerns the peculiarities of training monkeys to perform the DOA task. Although this task is concerned with object features, task acquisition was impeded at various stages of training when monkeys abandoned the correct, object-oriented alternation response and instead selected alternate wells without regard for the particular features of the object covering them. This adoption of a spatially oriented response strategy usually occurred when the task contingencies were made more difficult by lengthening the intertrial delay interval (en route to the target of 12 $\mathrm{sec}$ ) even after the monkey had successfully demonstrated the object alternation response at shorter delay intervals.

\section{LCGU rates prefrontal, parietal, and temporal cortex regions of interest}

In the principal sulcus, glucose utilization rates for monkeys performing working memory tasks were significantly enhanced relative to glucose utilization rates measured for monkeys performing the control tasks $[F(1,12)=6.58, p<0.03$; Table 2]. Group mean comparisons showed that LCGU in the WORK group was augmented by $19 \%$. LCGU rates for individual monkeys in the WORK group ranged from 60.90 to $87.85 \mu \mathrm{mol} /$ $100 \mathrm{gm} / \mathrm{min}$ (Fig. 3). In the CONT group, individual LCGU rates for the principal sulcus exhibited a wider range of values:
$36.86-91.90 \mu \mathrm{mol} / 100 \mathrm{gm} / \mathrm{min}$, largely because of one monkey that performed the VD task and whose LCGU rates in the principal sulcus as well as in the inferior parietal cortex were consistently higher than other monkeys of the CONT group. Except for the data of this monkey, there was little betweengroup overlap in individual monkey's median LCGU rates for the principal sulcus as shown in Figure 3.

Across all monkeys, individual median LCGU rates tended to be higher $(7-8 \%)$ in the posterior half of the principal sulcus measurement region relative to the anterior half suggesting a subtle functional parcellation of the principal sulcus. Mean LCGU for the WORK group was $68.14 \mu \mathrm{mol} / 100 \mathrm{gm} / \mathrm{min}$ anteriorly and $73.10 \mu \mathrm{mol} / 100 \mathrm{gm} / \mathrm{min}$ posteriorly, and mean LCGU for the CONT group was 56.53 and $61.29 \mu \mathrm{mol} / 100$ $\mathrm{gm} / \mathrm{min}$, for the anterior and posterior portions of the principal sulcus, respectively. Interestingly, five of nine monkeys in the WORK group showed this trend whereas higher posterior principal sulcus glucose utilization rates were seen for all six monkeys of the CONT group. This disparity, however, had no effect on our main finding as working memory performance yielded a significant enhancement of LCGU in each portion of the principal sulcus when these data were considered separately [anterior: $F(1,12)=6.25, p<0.03 ; F(1,12)=4.92, p<0.05]$.

The box arrays used to measure LCGU in the principal sulcus were regrouped to provide LCGU rates for subareas of the principal sulcus that coincide with the topography of parietal-prefrontal projections as described by the anatomical data of $\mathrm{Ca}$ - 
Table 1. Behavioral results for individual monkeys

\begin{tabular}{llll} 
Task & $\begin{array}{l}\text { Training } \\
\text { sessions }\end{array}$ & \multicolumn{2}{l}{ 2DG test performance } \\
\cline { 2 - 4 } & & Trials & \% Correct \\
\hline
\end{tabular}

Delayed spatial response

$\begin{array}{llll}\text { DR1 } & 8 & 143 & 96 \\ \text { DR2 } & 1 & 128 & 84 \\ \text { Mean } & 5 & 136 & 90\end{array}$

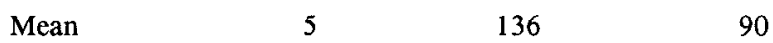

Delayed spatial alternation

DA1, $12 \mathrm{sec} \quad 5 \quad 160$

DA2, $12 \mathrm{sec} \quad 23$

DA3, $30 \mathrm{sec} \quad 8 \quad 62$

DA4, $30 \mathrm{sec} \quad 13 \quad 87$

Mean 12

Delayed object alternation

$\begin{array}{cl}\text { DOA1 } & 18 \\ \text { DOA2 } & 32 \\ \text { DOA3 } & 25 \\ \text { Mean } & 25\end{array}$

Visual pattern discrimination

VD1
VD2
VD4
Mean
Sensory-motor control
SM1
SM2
$\quad$ Mean

Training sessions refers to the number of testing sessions required for monkeys to achieve criterion performance on preliminary versions of their task. The trials and performance scores shown are for the 45 min test following the injection of ${ }^{14} \mathrm{C}-2 \mathrm{DG}$. Session data and performance scores are not given for monkeys tested on the sensory-motor control task as there was no mnemonic requirement for this task.

${ }^{a}$ Mean for monkeys tested on the delayed spatial alternation task using $15 \mathrm{sec}$ delay intervals.

${ }^{b}$ Mean for monkeys tested on the delayed spatial alternation task using $30 \mathrm{sec}$ delay intervals.

vada and Goldman-Rakic (1989) and schematized in Figure 4 (left). Note that the principal sulcus box array did not wholly encompass the territories of 7A, 7B, 7IP, and 7M interconnections because, for example, the principal sulcus measurement area defined here did not include much cortex on the dorsal surfacc (sce Figs. 1,2), superior to the principal sulcus, which has been cited as containing terminals of projection neurons in parietal subareas 7A and 7M (Cavada and Goldman-Rakic, 1989). Furthermore, the 7IP connections are not shown in Figure 4 as these connections occupy portions of the sulcus that are posterior to the coronal section illustrated. The WORK group's mean LCGU was enhanced by $16-22 \%$ relative to the CONT group in each subarea considered separately (Fig. 4, right). In the principal sulcus region corresponding to parietal area $7 \mathrm{~B}$ projections $\mathrm{LCGU}$ was enhanced by $22 \%$ in the WORK group relative to the CONT group [22\% enhancement; $F(1,12)$ $=6.30, p<0.03]$. The WORK group's LCGU rate was also significantly augmented in principal sulcus areas corresponding to anatomical connections with parietal subarea $7 \mathrm{~A}[19 \%$ enhancement; $F(1,12)=5.11, p<0.05]$, subarea $7 \mathrm{M}[18 \%$ enhancement; $F(1,12)=6.30, p=0.02]$, and subarea 7IP [16\% enhancement; $F(1,12)=4.55, p=0.054]$.

Like the results for the principal sulcus, LCGU in all three
Table 2. Mean LCGU rates $(\mu \mathrm{mol} / 100 \mathrm{gm} / \mathrm{min}$, + SFM) for the working memory and control group of monkeys in the principal sulcus region of prefrontal cortex, $7 \mathrm{IP}, 7 \mathrm{~A} \& 7 \mathrm{~B}$, and $7 \mathrm{M}$ subareas of inferior parietal cortex and in auditory cortex

\begin{tabular}{lll} 
& Working memory & Control group \\
\cline { 2 - 3 } Principal sulcus & $68.98 \pm 2.79^{*}$ & $57.99 \pm 7.74$ \\
Inferior parietal cortex & & \\
$\quad$ 7IP & $64.73 \pm 2.54^{*}$ & $57.33 \pm 5.06$ \\
7A \& 7B & $57.33 \pm 2.29^{*}$ & $51.12 \pm 3.53$ \\
7M & $60.00 \pm 2.84^{*}$ & $49.90 \pm 4.02$ \\
Auditory cortex & $80.50 \pm 3.19$ & $81.14 \pm 4.92$
\end{tabular}

* Cortical areas in which LCGU rates for the working memory group were significantly enhanced relative to the control group.

parietal subareas was significantly enhanced by working memory performance (Fig. 3). Compared to the CONT group, mean LCGU rates for the WORK group were enhanced by $11 \%$ in area 7IP $[F(1,11)=8.53, p<0.02]$ and by $12 \%$ in the combined $7 \mathrm{~A}$ and $7 \mathrm{~B}$ gyrus region [7B: $F(1,11)=16.26 ; p<0.01]$. The largest difference between groups was observed for arca $7 \mathrm{M}$, wherein LCGU for the WORK group was enhanced by $20 \%$ relative to the CONT group $[F(1,11)=9.66, p=0.01]$. This differential was largely due to the decreased LCGU rates of the CONT group, particularly in comparison to this group's mean LCGU for area 7IP (Table 2).

LCGU rates in the auditory cortex of all monkeys were generally higher than the LCGU rates measured in either parietal or prefrontal cortex (Fig. 3, Table 2). In contrast with the data for the principal sulcus and the inferior parietal cortex however, LCGU rates in the auditory cortex of the WORK and CONT groups were not significantly different $[F(1,11)=0.01$, NS] Indeed, mean LCGU rates were 80.50 and $81.14 \mu \mathrm{mol} / 100 \mathrm{gm} /$ min for the WORK and CONT groups, respectively (Table 2).

\section{WORK task parameters and LCGU}

Previously, we reported an association between working memory-task difficulty and LCGU rates in the thalamus (Friedman et al., 1990b). In the present data set however, the LCGU rates of monkeys performing the WORK tasks were closely coupled and did not appear to vary much by task (Fig. 3). Indeed, a Pearson correlation analysis of WORK-task difficulty (rankings in terms of difficulty were DOA > DA > DR; see above) and the WORK group's LCGU (ratios were used as described in Materials and Methods) showed no significant correlation between WORK-task difficulty and glucose utilization ratios. This was true for all of the cortical regions measured. On the other hand, when both WORK and CONT tasks were included in the analysis using the ranking DOA $>\mathrm{DA}>\mathrm{VD}>\mathrm{DR}>\mathrm{SMC}$ (see above), a significant positive correlation between difficulty and LCGU ratios was obtained for the principal sulcus overall ( $\mathbf{r}=0.61, \mathrm{df}=13, p<0.02$, two-tail) and for its subcomponents ( $\mathrm{r}$ range $=0.52-0.78, \mathrm{df}=13, p<0.05$, two-tail). A significant positive association of task difficulty and LCGU also was obtained for parietal subarea $7 \mathrm{M}(\mathbf{r}=0.67, \mathrm{df}=12, p<0.01$, two-tail). However, there was no significant correlation between task difficulty and LCGU for the other parietal regions measured nor for auditory cortex ( $\mathrm{r}$ range $=0.14-0.42$, $\mathrm{df}=12, \mathrm{NS}$ ).

Pearson correlation analyses between LCGU ratios and the performance accuracy of each monkey on its respective task (Scores), and between LCGU ratios and the number of trials 


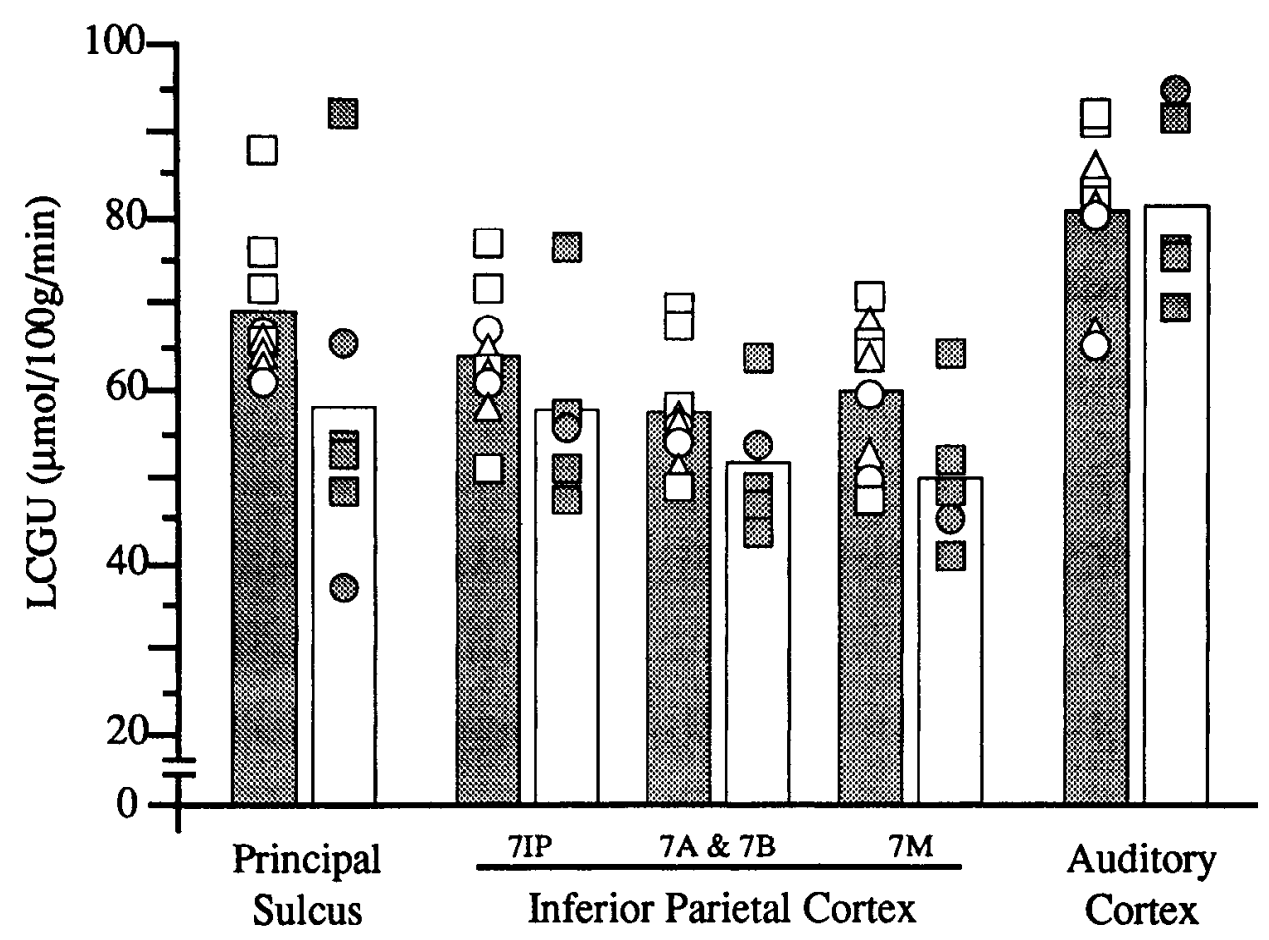

Figure 3. LCGU rates for monkeys performing working memory tasks and control tasks in the principal sulcus, inferior parietal cortex, and auditory cortex. Each symbol represents the median LCGU for individual monkeys throughout the designated measurement region. Bars indicate the mean for each group per area. completed during the 2DG session (Trials) also were computed. The Scores analysis necessarily precluded consideration of the data of monkeys in the CONT group that performed the SMC task, as response accuracy was irrelevant in these instances. Excluding these monkeys, a significant negative correlation was obtained between Scores and LCGU ratios only in parietal subarea $7 \mathrm{M}(\mathbf{r}=-0.73, \mathrm{df}=11, p<0.01$, two-tail). For the WORK group alone, no significant correlation coefficients were obtained although, again for parietal area $7 \mathrm{M}$, the calculated Pearson $\mathbf{r}$ coefficient suggested the association of higher LCGU ratios with lower performance scores $(r=-0.66, \mathrm{df}=7, p<0.10$, twotail). Not surprisingly, for the CONT group alone, no significant correlations were obtained given the small number of monkeys in this group.

The Trials analysis revealed significant correlations between LCGU ratios and the number of trials completed only for the
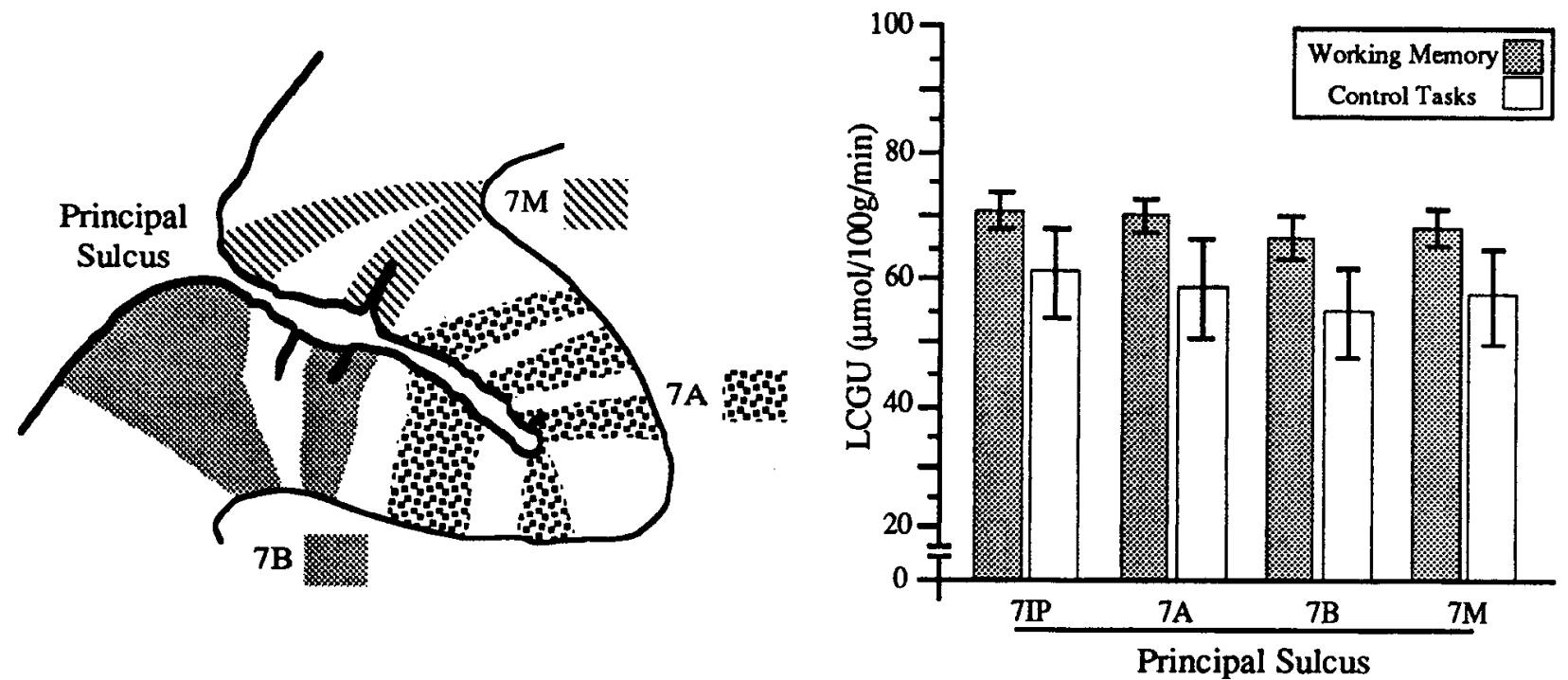

Figure 4. Mean LCGU rates for working memory task and the control task group of monkeys in subregions of the principal sulcus corresponding to the topography of prefrontal-inferior parietal anatomical connections. The diagram of the principal sulcus shown on the left depicts the topography of these connections as described by Cavada and Goldman-Rakic (1989). The topography of connections with parietal area 7IP is not shown as its territory is situated more posteriorly than the coronal level of section depicted here. 


\section{Prefrontal Cortex}

Figure 5. Digitized images of representative autoradiographs of coronal brain sections through the principal sulcus $(P S)$ region of prefrontal cortex (top); the anterior inferior parietal cortical area (middle) containing subarea 7B, a portion of 7IP, and the auditory cortex measurement area [within the lateral sulcus ( $L S)$; see also Fig. 1]; and the more posterior inferior parietal cortical area containing subareas $7 \mathrm{~A}, 7 \mathrm{M}$, and a portion of 7IP. Autoradiographs were digitized as described in Materials and Methods and electronically transferred to a Macintosh computer and reproduced using a thermal printer. The gray scale (bottom right) units are for LCGU: $\mu \mathrm{mol} / 100 \mathrm{gm} / \mathrm{min}$. Notice the presence of discrete regions of higher LCGU intensity within the ventral bank of the principle sulcus and elsewhere.

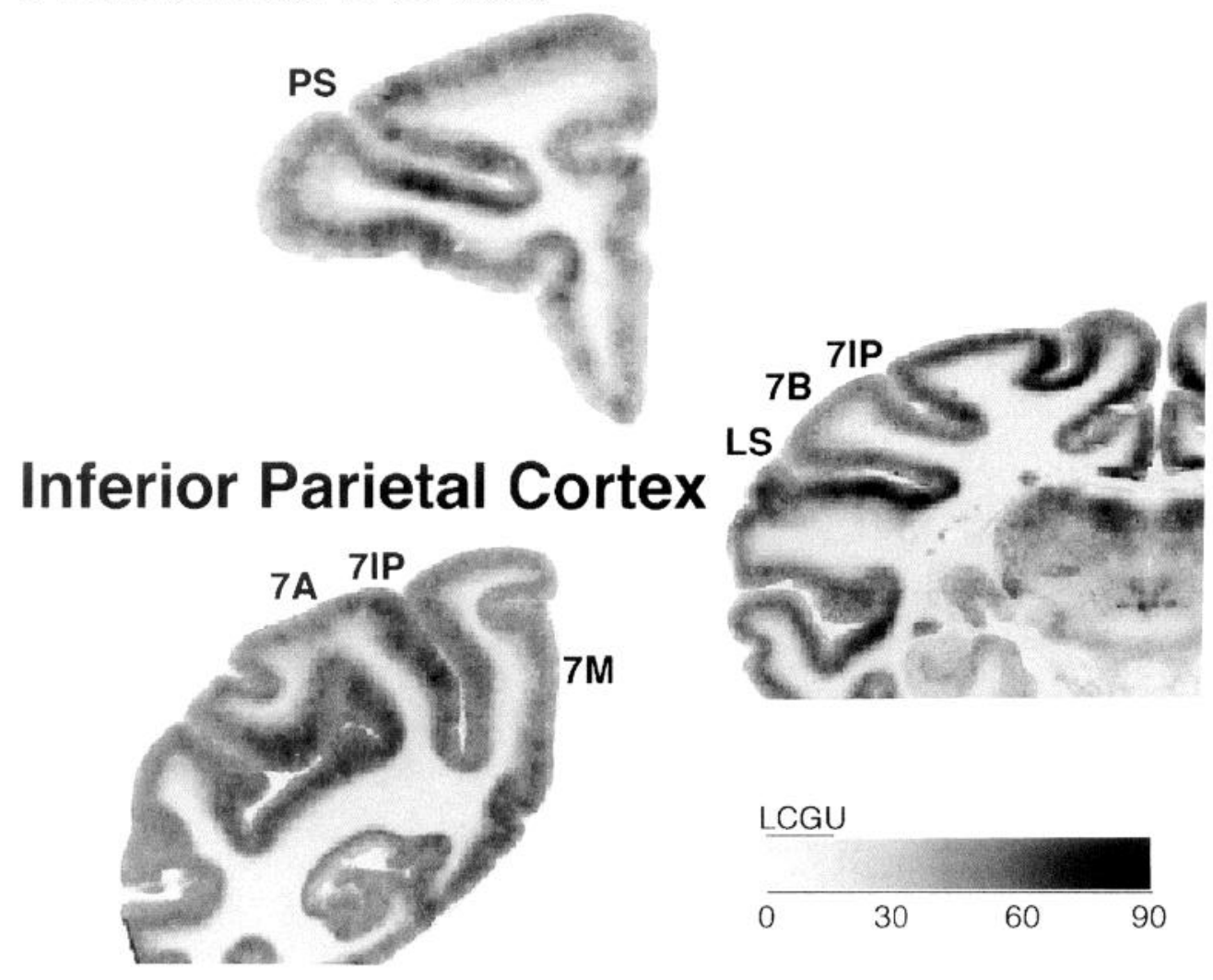

monkeys of WORK group considered separately. Within the WORK group, the Trials variable was positively associated with LCGU ratios in the component of the principal sulcus corresponding to 7IP projections $(\mathbf{r}=0.82, \mathrm{df}=7, p<0.01$, twotail) as well as in parietal areas 7IP $(\mathbf{r}=0.76, \mathrm{df}=7, p<0.02$, two-tail) and the combined parietal areas 7A and 7B $(r=0.74$, $\mathrm{df}=7, p<0.05$, two-tail).

\section{Patterns of $2 D G$ uptake}

As we have reported earlier in the case of the thalamus and hippocampal formation (Friedman and Goldman-Rakic, 1988; Friedman et al., 1990b), it was not apparent from the qualitative pattern of ${ }^{14} \mathrm{C}$-2DG uptake across the cortical areas measured whether individual monkeys had performed working memory or control tasks. Representative autoradiograph images showing a portion of the principal sulcus, inferior parietal cortex, and auditory cortex regions measured in the present report are shown in Figure 5. Thus, within a cortical area neither the laminar distribution of ${ }^{14} \mathrm{C}-2 \mathrm{DG}$ nor the areal patterning of $2 \mathrm{DG}$ uptake differentiated the two experimental groups.

The laminar distribution of ${ }^{14} \mathrm{C}-2 \mathrm{DG}$ uptake (translated to LCGU) is shown for representative $1 \mathrm{~mm}$ samples of principal sulcus, parietal and auditory cortex in Figure 6. Despite differences in the extent of specific layers, the patterns across these cortical areas are notable for their similarity. Generally, peak LCGU rates were measured in the supragranular layers II and III. The fluctuation of LCGU rates across cortical layers, how- ever, was less graded in the principal sulcus and auditory cortex relative to the broader pattern evidenced in parietal areas 7IP, 7A, 7B, and 7M. Discrete column-like areas of dense ${ }^{14} \mathrm{C}-2 \mathrm{DG}$ uptake were frequently evident in the principal sulcus and found relatively consistently across monkeys. Figure 5 (top) shows two such columns in the ventral bank of the principal sulcus, and the distribution of LCGU across the cortical layers for one of these is shown in Figure 6 (middle panel of right column). Across this column of increased ${ }^{14} \mathrm{C}$-2DG uptake, LCGU rates were generally higher in all cortical layers but this was most noticeable in infragranular layers II and III as well as in layer IV (compare top and middle panels of right column in Fig. 6). Discrete column-like areas of increased ${ }^{14} \mathrm{C}$-2DG uptake also were noted in the inferior parietal cortex and in the auditory cortex. The specific characteristics of these areas are presently under investigation.

\section{Discussion}

The 2DG method has previously been shown to be an efficacious tool in the monkey for examining sensory and/or motor processing of normal and dysfunctional brains (e.g., Deuel and Collins, 1984; Juliano and Whitsel, 1987). The results of the present experiment further emphasize that the methodology provides a mechanism for representing, and understanding the topology of cerebral activation underlying cognitive processing in the monkey. The main finding here was that glucose utilization both in the principal sulcus and in the inferior parietal

Figure 6. The laminar distribution of LCGU as measured in representative sections from subareas of the posterior parietal cortex, the principal sulcus and the auditory cortex. Shaded bars mark the extend of layer I and layer IV. The principal sulcus is represented twice. The data for one of 


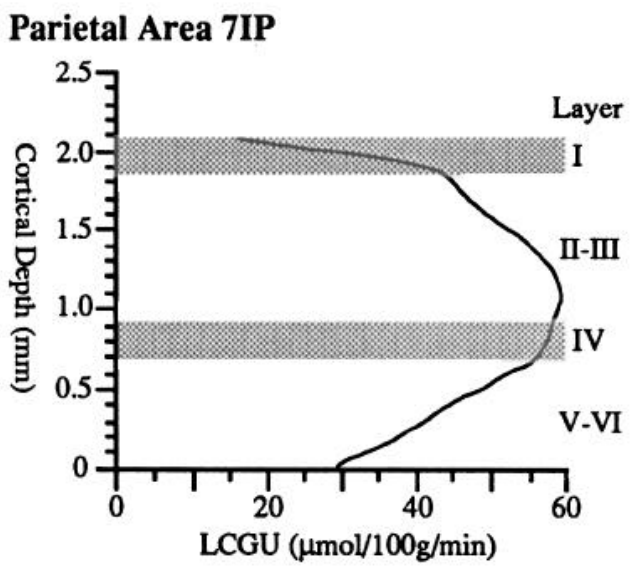

Parietal Area 7A

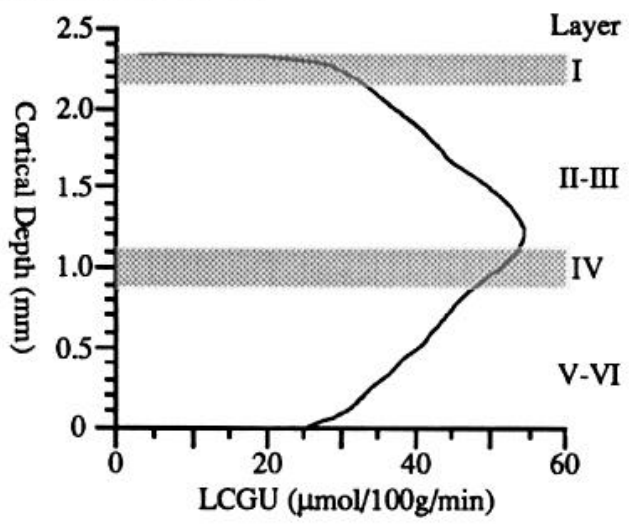

Parietal Area 7B

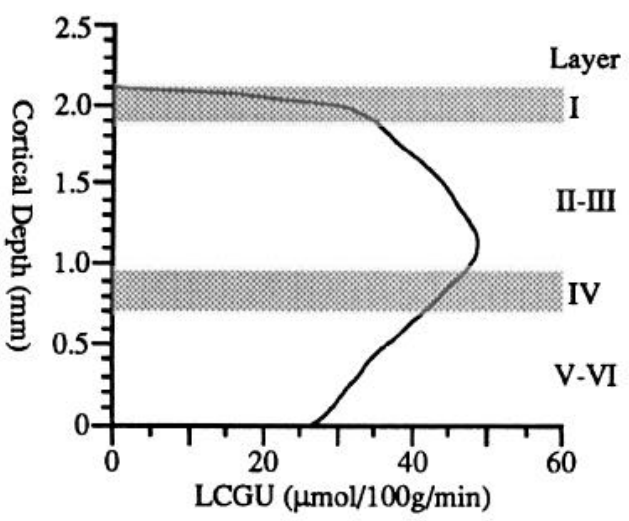

Parietal Area 7M

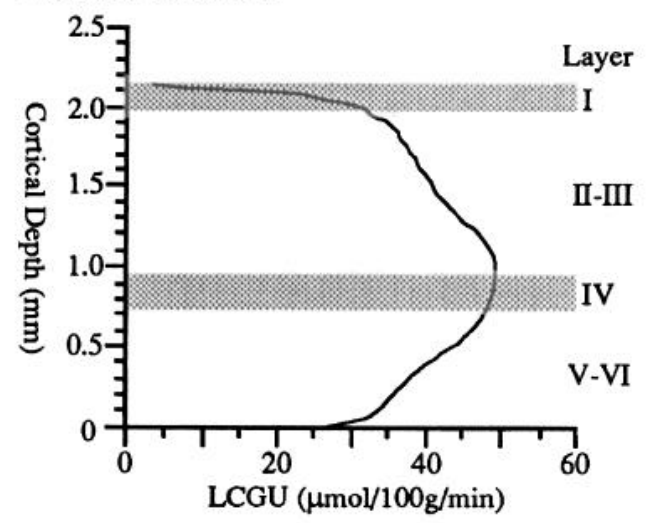

Principal Sulcus

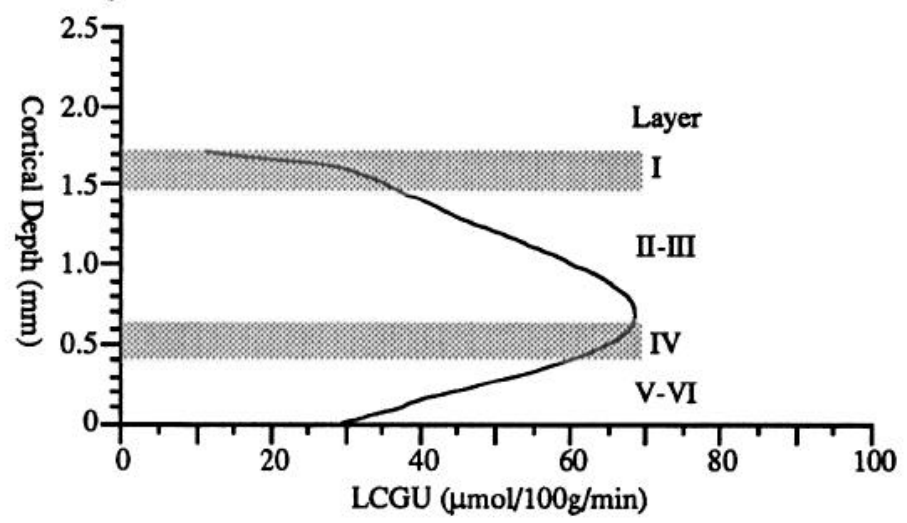

Principal Sulcus *
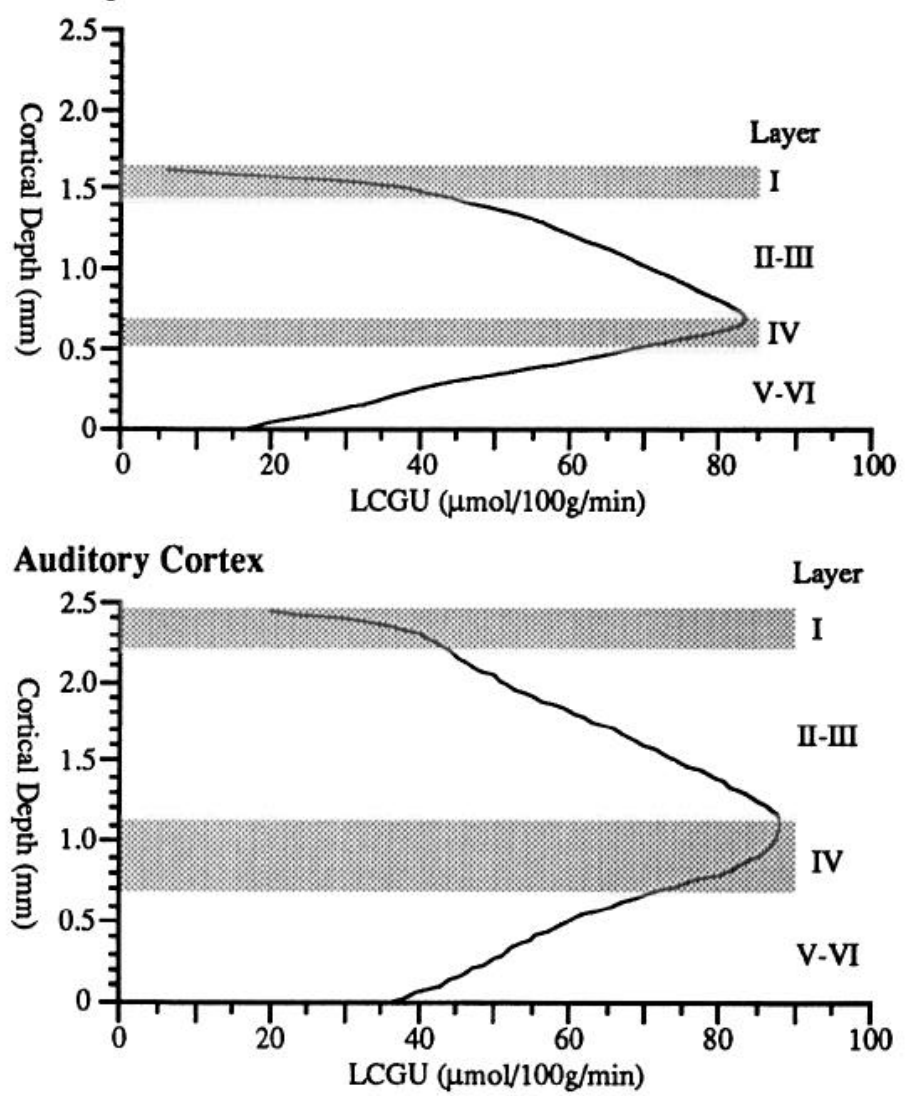

these graphs (right top) was taken from a $1 \mathrm{~mm}$ swath of cortex that was not remarkably distinct (patternwise) from its surround. The data for the second graph (right middle, marked by the asterisk) was taken from a $1 \mathrm{~mm}$ swath of cortex that included one of the discrete zones, or columns, of high LCGU rates in the ventral bank of the principal sulcus that is shown in Figure 5 (top). 
cortex is influenced by the kind of cognitive task that a monkey engages in. Performance on tasks that required working memory processing produced a significant enhancement in glucose utilization rates in these regions of dorsolateral prefrontal and parietal association cortex relative to glucose utilization rates in the same cortical regions of a second group of monkeys that performed tasks that did not specifically engage working memory processing. Importantly, working memory performance did not appear to instigate a global (cerebral) enhancement of glucose use as indicated both in the present study by the finding that auditory cortex LCGU rates were nearly identical for both groups of monkeys, and in our earlier reports on diencephalic (Friedman et al., 1990b) and limbic brain regions (Friedman and Goldman-Rakic, 1988).

These 2DG results further substantiate the association of the dorsolateral prefrontal cortex with working memory processing in the monkey and implicate the inferior parietal cortex as a functional collaborator in this process. Whereas much experimental and clinical research supports the association of dorsolateral prefrontal cortex function and working memory processing (see below), this is not the case for the inferior parietal cortex, for which previous studies stress an involvement in visuospatial perception and/or sensory-motor integration functions (see below). However, coactivation of these association cortical regions clearly does not imply functional identity. Indeed, the contribution of these cortical regions to the performance of the working memory tasks can be partially dissociated on the basis of differences in the relationship of LCGU in these areas to various behavioral task parameters.

The present 2DG results for the principal sulcus and inferior parietal cortex, taken together with our earlier findings from the thalamic trajectories of these association cortical regions (Friedman et al., 1990b, 1991), suggest that both cortices represent cortical nodes in a distributed neural network important for working memory in the monkey: the principal sulcus, by virtue of its executive role in spatial working memory per se, and the inferior parietal cortex, by virtue of its role in the perceptual/ attentive mechanisms underlying selection of the appropriate stimulus/response in these complex tasks (e.g., Hyvarinen, 1982; Mountcastle et al., 1984). These issues are discussed below.

\section{The principal sulcus and spatial working memory}

The enhancement of LCGU in the principal sulcus of monkeys performing working memory tasks is consistent with the wealth of literature linking this association cortex with spatial mnemonic functions (for review, see Goldman-Rakic, 1987). Indeed, delayed spatial response and delayed spatial alternation (e.g., Jacobsen 1937; Mishkin and Pribram, 1956; Goldman and Rosvold, 1970) are the cardinal spatial mnemonic tasks used to assess and interpret the behavioral deficits following ablation of this cortex, and both of these tasks rely upon the capacity to use internalized representations of just-preceding events to guide performance. We have argued (Goldman-Rakic, 1987; Goldman-Rakic and Friedman, 1991) that this capacity is a reflection of working memory processing in monkeys similar to that in human cognition (e.g., Just and Carpenter, 1985; Baddeley, 1986). Clinically, a homologous genre of tests is used to assess prefrontal function in the human, for example, the Wisconsin Card Sorting Task (Milner, 1963, 1964), the Tower of London test (Shallice, 1982), and the Stroop test (Perret, 1974), and these tests similarly require performance that is based on a dynamic internalized record rather than on any explicit, long-term as- sociation of external stimuli (Goldman-Rakic, 1987). Impaired performance on these tasks is identified with prefrontal cortical damage (for review, see Stuss and Benson, 1986; GoldmanRakic, 1987; Fuster, 1989). A deficiency in the generation of responses based on internal representations also is evident in the impaircd performance of patients with frontal brain damage on fluency tasks, whether linguistic (Milner, 1964) or spatial (Jones-Gotman and Milner, 1977). Although the latter paradigms fit less readily into the experimental template, the overall profile of these cognitive impairments indicates that in the human, as in the nonhuman primate, working memory processing represents a major element of prefrontal cortical function.

The obvious common denominator across the tasks of the WORK group was their working memory requirement. While these tasks differed both with respect to their level of difficulty, and with respect to whether they relied upon working memory processing for spatial or object features, the principal sulcus LCGU rates for monkeys performing the different (spatial and nonspatial) working memory tasks were largely intermixed. These findings suggest a preeminent role of the mnemonic component of the WORK tasks, rather than of the particular features of these tasks, in enhancing LCGU rates in the principal sulcus. Overall, the literature generally supports the basic findings: reversible inactivation (cooling) of the dorsolateral prefrontal cortex impairs the performance of monkeys on delayed match-tosample, a nonspatial working memory task (Bauer and Fuster, 1976), and electrophysiological recordings in monkeys performing this task indicate that populations of prefrontal cortical neurons are responsive to nonspatial attributes of visual stimuli (Quintana et al., 1988; Yajeya et al., 1988). This is not to deny a potential influence of "task difficulty" in enhancing LCGU rates. Indeed, this parameter differentiates the data of the principal sulcus from that of the inferior parietal cortex (except for area $7 \mathrm{M}$ ) because there was a positive correlation between LCGU rates and task difficulty for the principal sulcus data only. It may be that working memory tasks are inherently more difficult because they rely on recall whereas associative memory tasks rely more on recognition memory. However, further verification of this issue awaits experiments using associative memory tasks of greater difficulty.

It should be noted, however, that the DOA task results raise several additional issues. First, DOA task performance has not been specifically related to principal sulcus function in previous reports. In the few studies that have used the DOA paradigm, prefrontal cortical ablations that include the principal sulcus produce deficits in performance (Pribram and Mishkin, 1956; Mishkin et al., 1969) but the longevity of this deficit appears mild compared to the effect of lesions involving the adjacent ventral convexity cortex (Mishkin et al., 1969; Mishkin and Manning, 1978). It is important that these earlier studies used a shorter, $5 \mathrm{sec}$ intertrial interval rather than the $12 \mathrm{sec}$ interval used in the present 2DG study; the temporal delay may be particularly relevant for demonstrating principal sulcus involvement. However, while not exactly addressing our finding that LCGU in the principal sulcus was enhanced in monkeys performing the DOA task, as well as the DR and the DA tasks, these earlier reports do raise the possibility that the principal sulcus may not be the site of optimal elevation in LCGU rates for monkeys performing DOA. Indeed, more recent electrophysiological evidence suggests that prefrontal cortex of the inferior and superior convexity may be particularly related to object-feature components of memory tasks (Quintana et al., 
1989; Wilson et al., 1993). Analysis of the degree of activation of these areas is a logical next step in resolving the issue of focal contributions to nonspatial memory.

Finally, although DOA is ostensibly concerned with object feature memory, it is difficult to divorce this task fully from the spatial domain. Indecd, the motor response requirement of this task is spatially directed. But, in addition, the influence of spatial cues was frequently obvious during the testing regimen. As noted in the Results, monkeys periodically reverted to a spatial strategy: alternating their responses to the left and right food wells without regard to the object covering these wells, when the mnemonic contingencies were made more difficult by increasing the intertrial interval. Indeed, the large number of errors made by these monkeys on the $2 \mathrm{DG}$ test date also suggests that this sort of "spatial intrusion" was occurring. Mishkin and Manning (1978) also provided anecdotal evidence that spatial factors interfered with the monkey's mastery of the task. The intrusion of spatial alternation responses in an object alternation paradigm seems indicative of the very compelling influence commanded by spatial context. Further resolution of this issue awaits an examination of metabolic activity in the principal sulcus of monkeys performing working memory tasks that are nonspatial both in their motor response requirement as well as in their mnemonic contingencies.

\section{Parietal cortex and visuospatial-motor integration}

There is an overall symmetry in the results of studies of the principal sulcus in monkeys as they indicate electrophysiologically (Fuster, 1973; Niki, 1974; Funahashi et al., 1989, 1990), behaviorally (Goldman et al., 1971), and metabolically, in the case of the present findings, a role for this association cortex in working memory processing, particularly for the spatial domain. While there are numerous experimental results attributing visuospatial functional properties to the inferior parietal cortex in the monkey, this cortex is not also commonly associated with memory processing. Thus, neuronal activity in the inferior parietal cortex is responsive to different sensory modalities (e.g., visual, somatosensory) and to different response modalities (e.g., directed eye and hand/arm movements) (e.g., Hyvarinen and Poranen, 1974; Lynch et al., 1977; Mountcastle et al., 1975; Robinson et al., 1978; Rolls et al., 1979; Koch and Fuster, 1989), with modality specificity being regionally distributed at least with respect to areas $7 \mathrm{~A}$ and $7 \mathrm{~B}$ of the inferior parietal gyrus (Hyvarinen, 1981; see also Koch and Fuster, 1989). Further, cells in the inferior parietal cortex may show an enhanced response to a visual stimulus when the stimulus is behaviorally relevant, as for example, when that stimulus is a target for an oculomotor response (Bushnell et al., 1981).

However, whether inferior parietal cortex lesions impair a monkey's performance on a particular task seems to rely more critically upon the nature of the requisite sensory discrimination or sensory-motor response than upon the mnemonic contingency. After inferior parietal cortex lesions, performance is not impaired on associative memory tasks calling for discriminations on the basis of stimulus features such as size, shape, pattern, or brightness (Mendoza and Thomas, 1975; Mishkin et al., 1982; Eacott and Gaffan, 1991), but lesions of this area do produce deficits when spatial orientation is the discriminative dimension (Mendoza and Thomas, 1975; Eacott and Gaffan, 1991), or when the response is based on a particular spatial relationship between stimuli, as in the landmark task (Pohl, 1973; Ungerleider and Brody, 1977; Mishkin et al., 1982). Fur- ther, inferior parietal cortex resection impairs performance on tasks that have no mnemonic contingencies such as bent-wire problems (Petrides and Iversen, 1979). On a more fundamental level, such monkeys present with difficulties in making accurate visually guided hand/arm movements (Hartje and Ettlinger, 1973; Deuel, 1977; LaMotte and Acuna, 1978; Dcucl and Regan, 1985; Faugier-Grimaude et al., 1985; Eacott and Gaffan, 1991).

Thus, the foregoing experimental studies imply that the present $2 \mathrm{DG}$ results showing an enhancement of metabolic activity in the inferior parietal cortex of monkeys performing the WORK tasks should be interpreted as reflecting not the mnemonic content of the tasks, but instead, their greater, or more distinctive, visuospatial or sensory-motor demands relative to the CONT tasks. Indeed, metabolic activity in the inferior parietal cortex, but not in the principal sulcus overall, was correlated with the nonmemorial, sensory-motor parameters of the tasks. Both the absolute number of responses made (Trials) and the accuracy of performance (Scores) were correlated with LCGU in one or more of the inferior parietal regions examined. In part, the "Trials" result may relate to the impaired eye-hand coordination, or "reaching deficit" of monkeys following inferior parictal cortex lesions. Just as the impaired reaching of monkeys with inferior parietal lesions does not reflect a pure motor deficit (e.g., DeRenzi, 1982, for review), the significant correlation of LCGU with the number of trials completed on the 2DG task also is not likely to have a "purely" motor explanation because the correlation was significant only for the WORK group, and yet the CONT group completed comparatively the same number of trials. Large proportions of cells in the inferior parietal cortex are activated by reaching movements (e.g., Hyvarinen and Poranen, 1974; Mountcastle et al., 1975). More recently, Quintana and Fuster (1993) emphasized the involvement of parietal cortex in the sensory-motor components of memory task performance in the monkey, noting that parietal units, more so than cells in dorsolateral prefrontal cortex, show changes in their firing rate that are associated with the direction of an arm movement at the time of the response. Thus, the correlation of "Trials" and metabolic activity in the inferior parietal cortex is in accord with the evidence showing the involvement of this cortex in the sensory-motor processing required for task performance. That these results were found specifically for the WORK group may relate to the relatively greater visuospatial complexity of the WORK tasks relative to the CONT tasks.

The"Scores" result showing a negative correlation of performance accuracy and LCGU in parietal area $7 \mathrm{M}$ is more difficult to clarify. It is interesting that WORK group versus CONT group differences were greatest for area $7 \mathrm{M}$ relative to the other parietal regions measured and that LCGU in this region also was associated with task difficulty. On the other hand, the "Scores" result largely echoes the main 2DG result because performance scores were generally lower for monkeys performing the working memory tasks and yet, LCGU was enhanced in this group. While there have been few experimental studies specifically focused on area 7M, Mishkin et al. (1982) included it in one of their lesion groups (their medial parieto-preoccipital lesion) and reported that this lesion produced a deficit in landmark task performance without also impairing performance on a visual pattern discrimination task. Recent anatomical findings suggest that area $7 \mathrm{M}$ is an important relay of visuospatial and visuomotor information to the prefrontal cortex (Cavada and Goldman-Rakic, 1993). Thus, the medial portion of the parietal 
cortex deserves further examination in studies of parietal cortex function and behavior in the monkey.

\section{Principal sulcus and inferior parietal cortex: functional parallels and differences}

In monkeys, and in humans, the behavioral impairments following damage to the inferior parietal cortex are readily dissociable from that following dorsolateral prefrontal cortex (reviewed above). As elaborated by Critchley (1953) and later by others (for review, see Lynch, 1980; DeRenzi, 1982), unilateral inferior parietal cortex damage in the human reliably produces a profound perceptual neglect for contralateral extrapersonal space. Inferior parietal cortex damage also impairs skilled finger movements (Pause and Freund, 1989) and the ability to imitate arm/hand motor sequences accurately (De Renzi et al., 1983; Kolb and Milner, 1983). Although this apraxia may also follow lesions of other cortical areas, it is most severe in instances of parietal cortex damage (De Renzi et al., 1983; Kolb and Milner, 1983; De Renzi and Lucchelli, 1988). Another permanent manifestation of this impairment is a patient's tendency to ignore stimuli presented to the damaged (contralateral) hemifield (Posner et al., 1982, 1984, 1987; Baynes et al., 1986; Petersen et al., 1989). It is noteworthy that, while patients sustaining frontal cortical damage initially may present symptoms of hemineglect (e.g., Heilman and Valenstein, 1972), the selective attention deficit is not a permanent feature in patients with unilateral frontal cortex damage (Petersen et al., 1989). On the other hand, patients sustaining frontal cortical damage show impairments on the Card Sorting Task that are not evident after parietal lobe lesions (Milner, 1963).

In contrast to the evidence from ablation studies, dissociating the functional contribution of the principle sulcus and inferior parietal cortex presents a greater challenge when considered in the context of a normal monkey performing specific behavioral tasks. The present $2 \mathrm{DG}$ results, for example, make this point: working memory performance enhanced LCGU in both regions, with the major difference being in the further association of the principal sulcus with memory task difficulty and the inferior parietal cortex with sensory-motor task parameters. These data suggest that the preferential enhancement of LCGU in the inferior parietal cortex may reflect a conjunction of sensory (visuospatial) and motor (response) aspects of the behavioral tasks rather than their explicit mnemonic specifications whereas the enhancement of LCGU in the principal sulcus may reflect mnemonic demand. In a similar vein, electrophysiological studies in monkeys performing on oculomotor delayed response-type paradigms show that cells in both the principal sulcus and inferior parietal cortex have many common receptive field properties that are selective to particular aspects of these tasks (Gnadt and Andersen, 1988; Chafee et al., 1989; Barash et al., 1991a,b). In the inferior parietal cortex, principally parietal areas $7 \mathrm{~A}$ and 7IP, a large percentage of neurons show directionally specific cell activities related to the visual cue, to the oculomotor response, and to the memory phase, that is, delay period-coupled activities, of the delayed saccade task (Gnadt and Andersen, 1988; Chafee et al., 1989; Barash et al., 1991a,b). These response profiles are remarkably similar to neuronal responses in the principal sulcus during performance of a similar oculomotor delayed response task (Funahashi et al., 1989, 1990; GoldmanRakic et al., 1993). Similar response profiles for dorsolateral prefrontal and inferior parietal neurons also have been reported in the context of manual-response memory tasks as well (Quin- tana and Fuster, 1992). However, a higher percentage of cue and response-related neurons relative to delay-period responsive neurons is found in the parietal cortex whereas in the prefrontal cortex, delay period-responsive cells predominate (Chafee et al., 1989; Goldman-Rakic et al., 1993). A similar bias in the response profiles of prefrontal and parietal cortical units in the monkey has been reported in the context of color matching and positional-discrimination tasks using manual responses (Quintana and Fuster, 1992). Like the 2DG results, therefore, these findings seem more indicative of a common influence of parietal and dorsolateral prefrontal association cortices in visuospatial processing than indicative of a role for parietal cortex in working memory processing.

Differentiating the contribution of the inferior parietal cortex and the principal sulcus region of prefrontal cortex in spatial working memory processing does not negate the necessary cooperation of these association cortical regions for such behavioral responses. Indeed, the $2 \mathrm{DG}$ results show that ${ }^{14} \mathrm{C}-2 \mathrm{DG}$ was most highly concentrated in the supragranular layers of cortex, which are known to be a locus of parietal and prefrontal interconnections (Schwartz and Goldman-Rakic, 1984; Andersen et al., 1990). Layers III and IV represent, at least in the visual cortical model (e.g., Rockland and Pandya, 1979), the origin and termination locus, respectively, for rostrally directed projection systems. In the prefrontal cortex, deep layer III and layer IV also mark the termination zones for mediodorsal thalamic projections (Giguere and Goldman-Rakic, 1988). Thus, the laminar focus of $2 \mathrm{DG}$ activity possibly reflects the influence of both thalamic and corticocortical projections - a suggestion also supported by our previous results showing that working memory performance enhances glucose utilization in the mediodorsal thalamus (Friedman et al., 1990b).

Like the electrophysiological studies reviewed above, PET studies and related imaging protocols have revealed many instances of coactivation of prefrontal and parietal cortices in humans. For example, in their early study of the organization of thinking, Roland and Friberg (1985) showed that blood flow levels increase in both the posterior parietal cortex and dorsolateral prefrontal cortex in subjects performing a spatial working memory operation: mental route finding. Subsequent studies using a variety of imaging protocols and behavioral tasks have also reported coactivation of dorsolateral prefrontal and parietal cortices (e.g., Frith et al., 1991; Pardo et al., 1991; Petrides et al., 1993a,b). It is difficult, at present, to provide a comparative synthesis of the human imaging literature in order to dissociate fully the functional activation patterns of these two cortices because different imaging protocols and different anatomical localization methods are used. It is clear, however, that although the types of behavioral paradigms that evoke the pattern of coactivation vary from study to study, their shared features include both a requirement for on-line organization of memorandum and response prioritics, and a rcquircment that subjects select from a myriad of stimuli those to which a subsequent response is warranted. As reviewed above, dorsolateral prefrontal association cortex is uniquely associated with the former and parietal association cortex is linked to the latter.

\section{References}

Andersen RA, Asanuma C, Essick G, Siegel RM (1990) Corticocortical connections of anatomically and physiologically defined subdivisions within the inferior parietal lobule. J Comp Neurol 296:65-113. Baddeley A (1986) Working memory. Oxford: Clarendon. 
Barash S, Bracewell RM, Fogassi L, Gnadt JW, Andersen RA (1991a) Saccade-related activity in the lateral intraparietal area. I. Temporal properties; comparison with area 7a. J Neurophysiol 66:1095-1108.

Barash S, Bracewell RM, Fogassi L, Gnadt JW, Andersen RA (1991b) Saccade-related activity in the lateral intraparietal area. II. Spatial properties. J Neurophysiol 66:1 109-1124.

Bauer RH, Fuster JM (1976) Delayed matching and delayed-response deficit from cooling dorsolateral prefrontal cortex in monkeys. J Comp Physiol Psychol 90:293-302.

Baynes K, Holtzman JD, Volpe BT (1986) Components of visual attention. Brain 109:99-114.

Bushnell MC, Goldberg ME, Robinson DL (1981) Behavioral enhancement of visual responses in monkey cerebral cortex. I. Modulation in posterior parietal cortex related to selective visual attention. J Neurophysiol 4:755-772.

Cavada C, Goldman-Rakic PS (1989) Posterior parietal cortex in rhesus monkey. I. Parcellation of areas based on distinctive limbic and sensory corticocortical connections. J Comp Neurol 287:393-421.

Cavada C, Goldman-Rakic PS (1993) Multiple visual areas in the posterior parietal cortex of primates. In: Progress in brain research, Vol 95 (Hicks TP, Molotchnikoff S, Ono T, eds), pp 123-137. New York: Elsevier.

Chafee M, Funahashi S, Goldman-Rakic PS (1989) Unit activity in the primate posterior parietal cortex during an oculomotor delayed response task. Soc Neurosci Abstr 15:786.

Critchley M (1953) The parietal lobes. London: Arnold.

De Renzi E (1982) Disorders of space exploration and cognition. New York: Wiley.

De Renzi E, Lucchelli F (1988) Ideational apraxia. Brain 111:11731185.

De Renzi E, Lucchelli F, Fagliono P, Vecchi A (1983) Performance of left brain-damaged patients on imitation of single and motor sequences: frontal and parietal patients compared. Cortex 19:333-343.

Deuel RK (1977) Loss of motor habits after cortical lesions. Neuropsychologia 15:205-215.

Deuel RK, Collins R (1984) The functional anatomy of frontal lobe neglect in the monkey: behavioral and quantitative 2-deoxyglucose studies. Ann Neurol 15:521-529.

Deuel RK, Regan DJ (1985) Parietal hemineglect and motor deficits in the monkey. Neuropsychologia 23:305-314.

Eacott MJ, Gaffan D (1991) The role of monkey inferior parietal cortex in visual discrimination of identity and orientation of shapes. Behav Brain Res 46:95-98.

Faugier-Grimaude S, Frenois C, Peronnet F (1985) Effects of posterior parietal lesions on visually guided movements in monkeys. Exp Brain Res 59:125-138.

Friedman HR, Goldman-Rakic PS (1988) Activation of the hippocampus and dentate gyrus by working memory: a 2-deoxyglucose study of behaving rhesus monkeys. J Neurosci 8:4693-4706.

Friedman HR, Bruce CJ, Goldman-Rakic PS (1990a) Double-label $\left[{ }^{3} \mathrm{H}\right] 2$-deoxyglucose and $\left[{ }^{14} \mathrm{C}\right]$ 2-deoxyglucose method for mapping brain activity underlying two experimental conditions in the same animal. In: Methods in neuroscience (Conn PM, ed), pp 389-412. New York: Academic.

Friedman HR, Janas J, Goldman-Rakic PS (1990b) Enhancement of metabolic activity in the diencephalon of monkeys performing working memory tasks: a 2-deoxyglucose study in behaving rhesus monkeys. J Cognit Neurosci 2:18-31.

Friedman HR, Bhalla S, Goldman-Rakic PS (1991) Metabolic activation of dorsolateral prefrontal and parietal cortex by cognitive processing: a 2-DG study in behaving rhesus monkeys. Soc Neurosci Abstr 17:135.

Frith CD, Friston KJ, Liddle PF, Frackowiak RSJ (1991) A PET study of word finding. Neuropsychologia 12:1137-1148.

Funahashi S, Bruce CJ, Goldman-Rakic PS (1989) Mnemonic coding of visual space in the monkey's dorsolateral prefrontal cortex. J Neurophysiol 61:331-349.

Funahashi S, Bruce CJ, Goldman-Rakic PS (1990) Visuospatial coding in primate prefrontal neurons revealed by oculomotor paradigms. $\mathrm{J}$ Neurophysiol 63:811-831.

Fuster JM (1973) Unit activity in the prefrontal cortex during delayedresponse performance: neuronal correlates of transient memory. $\mathrm{J}$ Neurophysiol 36:61-78.

Fuster JM (1989) The prefrontal cortex. New York: Raven.

Gellerman LW (1933) Chance orders of alternating stimuli in visual discrimination experiments. J Gen Psychol 42:207-208.
Giguere M, Goldman-Rakic PS (1988) Mediodorsal nucleus: areal, laminar, and tangential distribution of afferents and efferents in the frontal lobe of rhesus monkeys. J Comp Neurol 277:195-213.

Gnadt JW, Andersen RA (1988) Memory related mutor planning activity in posterior parietal cortex of macaque. Exp Brain Res 70: $216-220$

Goldman PS (1971) Functional development of the prefrontal cortex in early life and the problem of neuronal plasticity. Exp Neurol 32: 366-387.

Goldman PS, Rosvold HE (1970) Localization of function within the dorsolateral prefrontal cortex of the rhesus monkey. Exp Neurol 27: 291-304.

Goldman PS, Rosvold HE, Vest B, Galkin TW (1971) Analysis of the delayed alternation deficit produced by dorsolateral prefrontal lesions in the rhesus monkey. J Comp Physiol Psychol 77:212-220.

Goldman-Rakic PS (1987) Circuitry of primate prefrontal cortex and regulation of behavior by representational memory. In: Handbook of physiology, Vol 5, The nervous system (Plum F, ed), pp 373-417. Bethesda, MD: American Physiological Society.

Goldman-Rakic PS (1988) Topography of cognition: parallel distributed networks in primate association cortex. Annu Rev Neurosci 11: 137-156.

Goldman-Rakic PS, Friedman HR (1991) The circuitry of working memory revealed by anatomy and metabolic imaging. In: Frontal lobe function and dysfunction (Levin HS, Eisenberg HM, Benton AL, eds), pp 72-91. New York: Oxford.

Goldman-Rakic PS, Chafee M, Friedman HR (1993) Allocation of function in distributed circuits. In: Brain mechanisms of perception and memory: from neuron to behavior (Ono T, Squire L, Raichle ME, Perrett DI, Fukuda M, eds), pp 445-456. New York: Oxford.

Hartje W, Ettlinger G (1973) Reaching in light and dark after unilateral posterior parietal ablations in the monkey. Cortex 9:346-354.

Heilman KM, Valenstein E (1972) Frontal lobe neglect in man. Neurol 22:660-664.

Hyvarinen J (1981) Regional distribution of functions in parietal association area 7 of the monkey. Brain Res 206:287-303.

Hyvarinen J (1982) Posterior parietal lobe of the primate brain. Physiol Rev 62:1060-1129.

Hyvarinen J, Poranen A (1974) Function of the parietal association area 7 as revealed from cellular discharges in alert monkeys. Brain 97:673-692.

Jacobsen C F (1936) Studies of cerebral function in primates. Comp Psychol Monogr 13:3-60.

Jones-Gotman M, Milner B (1977) Design fluency: the invention of nonsense drawings after focal lesions. Neuropsychologia 15:653-674.

Juliano SL, Whitsel BL (1987) A combined 2-deoxyglucose and neurophysiological study of primate somatosensory cortex. J Comp Neurol 263:514-525.

Just MA, Carpenter PA (1985) Cognitive coordinate systems: accounts of mental rotation and individual differences in spatial ability. Psychol Rev 92:137-172.

Kennedy C, Sakurada O, Shinohara M, Jehle J, Sokoloff L (1978) Local cerebral glucose utilization in the normal conscious macaque monkey. Ann Neurol 4:293-301.

Koch KW, Fuster JM (1989) Unit activity in monkey parietal cortex related to haptic perception and temporary memory. Exp Brain Res 76:292-306.

Kolb B, Milner B (1981) Performance of complex arm and facial movements after focal brain lesions. Neuropsychologia 19:491-503.

LaMotte R, Acuna C (1978) Defects in accuracy of reaching after removal of posterior parietal cortex in monkeys. Brain Res 139:309326.

Lynch JC (1980) The functional organization of posterior parietal association cortex. Behav Brain Sci 3:485-534.

Lynch JC, Mountcastle VB, Talbot WH, Yin TCT (1977) Parietal lobe mechanisms for directed visual attention. J Neurophysiol 40:362389.

Mendoza JE, Thomas RK Jr (1975) Effects of posterior parietal and frontal neocortical lesions in the squirrel monkey. J Comp Physiol Psychol 80:170-182.

Mesulum M-M, Van Hoesen GW, Pandya DN, Geschwind N (1977) Limbic and sensory connections of the inferior parietal lobule (area PG) in the rhesus monkey: a study with a new method for horseradish peroxidase histochemistry. Brain Res 136:393-414.

Milner B (1963) Effects of different brain lesions on card sorting. Arch Neurol 9:100-111. 
Milner B (1964) Some effects of frontal lobectomy in man. In: The frontal granular cortex and behavior (Warren JM, Akert K, eds), pp 313-334. New York: McGraw-Hill.

Mishkin M, Manning FJ (1978) Non-spatial memory after selective prefrontal lesions in monkeys. Brain Res 143:313-323.

Mishkin M, Pribram KH (1956) Analysis of the effects of frontal lesions in monkey: variations of delayed response. J Comp Physiol Psychol 49:36-40.

Mishkin M, Vest B, Waxler M, Rosvold HE (1969) A re-examination of the effects of frontal lesions on object alternation. Neuropsychologia 7:357-363.

Mishkin M, Lewis ME, Ungerleider LG (1982) Equivalence of parietopreoccipital subareas for visuospatial ability in monkeys. Behav Brain Res 6:41-55.

Mountcastle VB, Lynch JC, Georgopoulos A, Sakata H, Acuna C (1975) Posterior parietal association cortex of the monkey: command functions for operations within extrapersonal space. J Neurophysiol 38: 871-908.

Mountcastle VB, Motter BC, Steinmetz MA, Duffy CJ (1984) Looking and seeing: the visual functions of the parietal lobe. In: Dynamic aspects of neocortical function (Edelman GM, Gall WE, Cowan WM, eds), pp 159-193. New York: Wiley.

Niki H (1974) Prefrontal unit activity during delayed alternation in the monkey. I. Relation to direction of response. Brain Res 68:185196.

Pandya DP, Sanides F (1973) Architectonic parcellation of the temporal operculum in rhesus monkey and its projection pattern. Z Anat Entwicklungsgesch 139:127-161.

Pandya DP, Seltzer B (1982) Intrinsic connections and architectonics of posterior parietal cortex in the rhesus monkey. J Comp Neurol 204:196-210.

Pardo JV, Fox PT, Raichle ME (1991) Localization of a human system for sustained attention by positron emission tomography. Nature 349 : 61-64.

Pause M, Freund H (1989) Role of parietal cortex for sensorimotor transformation: evidence from clinical observations. Brain Behav Evol 33:136-140.

Perret E (1974) The left frontal lobe of man and the suppression of habitual responses in verbal categorical behaviour. Neuropsychologia 12:323-330.

Petersen SE, Robinson DL, Currie JN (1989) Influences of lesions of parietal cortex on visual spatial attention in humans. Exp Brain Res 76:267-280.

Petrides M, Iversen SD (1979) Restricted posterior parietal lesions in the rhesus monkey and performance on visuospatial tasks. Brain Res 161:63-77.

Petrides M, Pandya DN (1984) Projections to the frontal cortex from the posterior parietal region in the rhesus monkey. J Comp Neurol 228:105-116.

Petrides M, Alivisatos B, Evans AC, Meyer E (1993a) Dissociation of human mid-dorsolateral from posterior dorsolateral frontal cortex in memory processing. Proc Natl Acad Sci USA 90:873-877.

Petrides M, Alivisatos B, Meyer E, Evans AC (1993b) Functional activation of the human frontal cortex during the performance of verbal working memory tasks. Proc Natl Acad Sci USA 90:878-882.

Pohl W (1973) Dissociation of spatial discrimination deficits following frontal and parietal lesions in monkeys. J Comp Physiol Psychol 82: 227-233.

Posner MI, Cohen Y, Rafal RD (1982) Neural systems control of spatial orienting. Philos Trans R Soc Lond [Biol] 298:187-198.
Posner MI, Walker JA, Friedrich FA, Rafal RD (1984) Effects of parietal injury on covert orienting of attention. J Neurosci 4:18631874.

Posner MI, Walker JA, Friedrich FA, Rafal RD (1987) How do the parietal lobes direct covert attention? Neuropsychologia 25:135-145.

Pribram KH, Mishkin M (1956) Analysis of the effects of frontal lesions in monkey. III. Object alternation. J Comp Physiol Psychol 49:41-45.

Quintana J, Fuster JM (1992) Mnemonic and predictive functions of cortical neurons in a memory task. Neuroreport 3:721-724.

Quintana J, Fuster JM (1993) Spatial and temporal factors in the role of prefrontal and parietal cortex in visuomotor integration. Cereb Cortex 3:122-132.

Quintana J, Yajeya J, Fuster JM (1988) Prefrontal representation of stimulus attributes during delay tasks. I. Unit activity in cross-temporal integration of sensory and sensory-motor information. Brain Res 474:211-221.

Quintana J, Fuster JM, Yajeya J (1989) Effects of cooling parietal cortex on prefrontal units in delay tasks. Brain Res 503:100-110.

Robinson DL, Goldberg ME, Stanton GB (1978) Parietal association cortex in the primate: sensory mechanisms and behavioral modulations. J Neurophysiol 41:910-932.

Rockland KS, Pandya DN (1979) Laminar origins and terminations of cortical connections of the occipital lobe in the rhesus monkey. Brain Res 179:3-20.

Roland PE, Friberg L (1985) Localization of cortical areas activated by thinking. J Neurophysiol 53:1219-1243.

Rolls ET, Perret D, Thorpe SJ, Puerto A, Roper-Hall A, Maddison S (1979) Response of neurons in area 7 of the parietal cortex to objects of different significance. Brain Kes 169:194-198.

Schwartz ML, Goldman-Rakic PS (1984) Callosal and intrahemispheric connectivity of the prefrontal association cortex in rhesus monkey: relation between intraparietal and principal sulcal cortex. J Comp Neurol 226:403-420.

Selemon LD, Goldman-Rakic PS (1988) Common cortical and subcortical targets of the dorsolateral prefrontal and posterior parietal cortices in the rhesus monkey: evidence for a distributed neural network subserving spatially guided behavior. J Neurosci 8:4049-4068.

Shallice T (1982) Specific impairments in planning. Philos Trans $R$ Soc Lond [Biol] 298:199-209.

Sokoloff L, Reivich M, Kennedy C, Des Rosiers MH, Patlak CS, Pettigrew KD, Sakurada O, Shinohara M (1977) The ${ }^{14} \mathrm{C}$-deoxyglucose method for the measurement of local cerebral glucose utilization: theory, procedure, and normal values in the conscious and anesthetized albino rat. J Neurochem 28:897-916.

Stuss DT, Benson DF (1986) The frontal lobes. New York: Raven.

Ungerleider LG, Brody BA (1977) Extrapersonal spatial orientation: the role of posterior parietal, anterior frontal, and inferotemporal cortex. Exp Neurol 56:265-280.

Wilson FAW, O'Scalaidhe SP, Goldman-Rakic PS (1993) Dissociation of object and spatial processing domains in primate prefrontal cortex. Science 260:1955-1958.

Winer BJ (1971). Statistical principles in experimental design. New York: McGraw-Hill.

Von Bonin G, Bailey P (1947) The neocortex of Macaca mulatta. Urbana: University of Illinois.

Yajeya J, Quintana J, Fuster JM (1988) Prefrontal representation of stimulus attributes during delay tasks. II. The role of behavioral significance. Brain Res 474:222-230. 